This is the author's final version of the work, as accepted for publication following peer review but without the publisher's layout or pagination.

The definitive version is available at

10.1016/j.eiar.2016.01.002

A game theory perspective on Environmental Assessment: what games are played and what does this tell us about decision making rationality and legitimacy?

Alan Bond* - School of Environmental Sciences, University of East Anglia, United Kingdom; Research Unit for Environmental Sciences and Management, North-West University, South Africa

Jenny Pope - Integral Sustainability, Australia; Research Unit for Environmental Sciences and Management, North-West University, South Africa

Angus Morrison-Saunders - Murdoch University, Australia; Research Unit for Environmental Sciences and Management, North-West University, South Africa

Francois Retief - Research Unit for Environmental Sciences and Management, North-West University, South Africa

*corresponding author 


\title{
A game theory perspective on Environmental Assessment: what games are played and what does this tell us about decision making rationality and legitimacy?
}

\begin{abstract}
Alan Bond* - School of Environmental Sciences, University of East Anglia, United Kingdom; Research Unit for Environmental Sciences and Management, North-West University, South Africa
\end{abstract}

Jenny Pope - Integral Sustainability, Australia; Research Unit for Environmental Sciences and Management, North-West University, South Africa

Angus Morrison-Saunders - Murdoch University, Australia; Research Unit for Environmental Sciences and Management, North-West University, South Africa

Francois Retief - Research Unit for Environmental Sciences and Management, North-West University, South Africa

* corresponding author

\begin{abstract}
Game theory provides a useful theoretical framework to examine the decision process operating in the context of environmental assessment, and to examine the rationality and legitimacy of decision-making subject to Environmental Assessment (EA). The research uses a case study of the Environmental Impact Assessment and Sustainability Appraisal processes undertaken in England. To these are applied an analytical framework, based on the concept of decision windows to identify the decisions to be assessed. The conditions for legitimacy are defined, based on game theory, in relation to the timing of decision information, the behaviour type (competitive, reciprocal, equity) exhibited by the decision maker, and the level of public engagement; as, together, these control the type of rationality which can be brought to bear on the decision. Instrumental rationality is based on self-interest of individuals, whereas deliberative rationality seeks broader consensus and is more likely to underpin legitimate decisions. The results indicate that the Sustainability Appraisal process, conducted at plan level, is better than EIA, conducted at project level, but still fails to provide conditions that facilitate legitimacy. Game theory also suggests that Sustainability Appraisal is likely to deliver 'least worst' outcomes rather than best outcomes when the goals of the assessment process are considered; this may explain the propensity of such 'least worst' decisions in practice. On the basis of what can be learned from applying this game theory perspective, it is suggested that environmental assessment processes need to be redesigned and better integrated into decision making in order to guarantee the legitimacy of the decisions made.
\end{abstract}

\section{Key words}

Game theory; environmental assessment; legitimacy; instrumental rationality; deliberative rationality; decision making 


\section{Linking rationality and legitimacy of EA with game theory}

Environmental Assessment (EA) was established based on a technical-rational model which argues that better information will lead to better decisions. This follows the logic that decision-makers display 'instrumental rationality' which in the context of EA means taking the decision, based on the evidence available, which best delivers the goals of EA. However, the goals of environmental assessment are considered to have changed over time from environmental advocacy to sustainable development (Morrison-Saunders and Fischer, 2006; Morrison-Saunders and Therivel, 2006), and there are contested meanings of sustainable development (Bond and Morrison-Saunders, 2011). This calls into question the extent to which instrumental rationality is possible, or desirable.

Another issue with decision makers displaying instrumental rationality is the argument that it allows powerful stakeholders to influence outcomes to meet their own ends. The theory is that through the application of instrumental rationality 'knowledge speaks to power' (Pope et al., 2013). But Cashmore and Axelsson (2013) argue that knowledge does not necessarily speak to power as power can control the knowledge made available to decision makers (Cashmore et al., 2008)

Owens et al. (2004, p.1947) argue that the contested decision-making (e.g. where the definition of sustainable development is contested, or the outcomes inequitable) creates decision legitimacy problems: "this brings us to another failure of the technical-rational model: appraisal based on contested judgments or frames loses legitimacy and becomes practically inadequate for delivering reasonably consensual policy outputs". Appelstrand (2002, p.285), writing about forestry policy, describes this problem of technical-rational decision-making failing to cope with contested values as a "legitimisation crisis". Suchman $(1995$, p.574) synthesizes understanding from wider literature to define legitimacy as " $a$ generalized perception or assumption that the actions of an entity are desirable, proper, or appropriate within some socially constructed system of norms, values, beliefs, and definitions". As such, legitimacy in the context of EA contains elements of goal framing (i.e. a common understanding of sustainability is needed) and of equity (i.e. the outcomes of the decision need to favour all stakeholders equally). We therefore define a legitimate EA process as one which all stakeholders agree is fair and which delivers an acceptable outcome for all parties. This is in line with the definition of Adger et al. $(2005, p .83)$ that legitimacy means "the extent to which decisions are acceptable to participants and non-participants".

Therefore to avoid the possibility of EA being manipulated for the instrumental ends of the powerful, Owens and Cowell (2002) argue that 'deliberative rationality' needs to be exercised. This involves a broad cross section of society agreeing the normative expectations (of sustainable development) that they could all live with (Gauthier, 2003). In addition, more inclusive participation is better able to deliver equity in decision making (see, for example, Kakonge, 1996; O'Faircheallaigh, 2010; Petts, 2003; Shepherd, 1997; Sinclair, 2002; Wiklund, 2011). It is widely recognised that the timing of the participation is crucial in order to facilitate deliberation, with early participation, as encompassed in the Arhus Convention (UNECE, 1998) being an essential precondition of a legitimate process (Agterbosch and Breukers, 2008). 
Deliberative rationality relies on broad participation of stakeholders, including members of the public. It is not to be confused with the type of deliberation that might take place in a decision-making committee that typifies many democratic systems. In these committees, a group (of elected representatives) make a decision which Kugler et al. (2012) argue simply reinforces the application of instrumental rationality. Kugler et al. $(2012, p .473)$ provide some hypotheses for why this might be the case, including "the social support of shared selfinterest (or, greed) hypothesis argues that groups are greedier than individuals because group members provide each other with support for acting in a selfish, in-group-oriented way"; and "the identifiability hypothesis, which proposes that in interindividual interactions players assume that they are identifiable and thus can be held accountable ... in intergroup interactions responsibility for a choice is by its very nature obscured". Thus deliberative rationality is not necessarily delivered by a decision-making committee.

Game theory has been defined as "the study of mathematical models of conflict and cooperation between intelligent rational decision-makers" (Myerson, 1991, p.1), and it assumes that rational decisions based on self-interest (i.e. exhibiting instrumental rationality) are made by players in a game where there are individual decision-makers (Poundstone, 1992). Different decision contexts can be modelled using different games (including cooperative games that allow for deliberation (Colman, 1995)), and these different games provide insights into the timing of information provision, the levels of engagement (i.e. extent of participation of stakeholders and so the extent to which deliberative rationality can be facilitated and legitimacy achieved), and the extent to which equity (also a prerequisite for legitimacy) is delivered. Where the decision context matches one of the games that is modelled through game theory, the outcomes in terms of decision rationality and legitimacy can potentially be predicted. As such, game theory can be applied to EA cases in order to investigate the rationality and legitimacy of the decision-making that takes place.

Thus it is clear that the technical-rational model of decision making subject to environmental assessment (EA)(at all levels: projects, plans, policies) is subject to criticism, and that the contested nature of the goals and outcomes of EA has led to a 'legitimisation crisis'. We argue that there is a need both to apply deliberative rationality in decision making to agree the goals of $E A$, and to focus more on the equity of outcomes, to facilitate greater legitimacy. Based on this context, in this paper we aim to examine the rationality and legitimacy of decision-making subject to project-level Environmental Impact Assessment (EIA), and to plan-level Sustainability Appraisal (SA) in England through the lens of game theory.

Applying game theory to EA decision contexts is a novel means of investigating and evaluating practice from the viewpoint of rationality and legitimacy. The next section of the paper introduces game theory, although it is necessarily brief as the literature on this topic is vast and we introduce the concepts without recourse to the mathematical proofs that underlie the usual application of the theories. This section introduces the games which will be matched against the EA processes. The third section explains our methodology for evaluating the rationality and legitimacy of English EIA and SA by setting out the analytical framework we have employed, and justifying the selection of case studies. The fourth section applies the method to the case study and discusses the implications of the results. Finally, conclusions are provided to clarify our learning in the context of the aim of the paper. 


\section{Overview of game theory literature}

In game theory, the basic concept is that there are two or more decision makers (called 'players'), each of which has a choice of ways of acting (Colman, 1995). In mathematical applications of game theory, it also has to be possible to quantify the preferences for decision outcome of each player in order to analyse the different possible outcomes. Different decision-making contexts are represented by different games which are played by players who are making rational decisions typically based on self-interest, i.e. displaying instrumental rationality (Schubik, 1982). The types of games are determined by the types (and number) of players and the types of decisions that have to be made. The development of game theory is credited to John von Neumann (Poundstone, 1992). The derivation of game theory was apparently based on observations of poker players, but Poundstone (1992) explains the basis for the theory through childhood games. He refers to cake division whereby to avoid two children fighting over which gets the biggest piece of cake, one child gets to cut the cake whilst the other then chooses which piece to eat (the cake slicing game). The argument is that the best strategy for the first child is to anticipate the second child will choose the largest piece, as a result the first child will likely seek to cut the cake evenly in order to get the optimum outcome. This is known as the 'minimax' principle whereby the cake cutter will maximum the minimum he/she will get. One of the bases of game theory is therefore the self-interest of players (Poundstone, 1992).

In the above description, the behaviour is reciprocal in that each player's decision has an effect on the outcome for the other. But the example is not typical. In the cake example both children can see the cake and the outcome is transparent, which is a key determinant of legitimacy in decision making (Jasanoff, 1997) and a basic principle for environmental assessment (International Association for Impact Assessment and Institute of Environmental Assessment, 1999). In reality the outcome is often more complex. Poundstone (1992) points to the frequent application of game theory to zero-sum games - i.e. those like poker where one player wins all the money that has been bet by all the individual players in the game, but all the other player have lost money. In a game of poker - all players exhibit self-interest, but only one player's self-interest is satisfied, everyone else loses and presumably feels aggrieved as a result.

Another game is known as the prisoner's dilemma. In this case of two game players, neither knows what the other will do. Each has two possible choices and so there are just four potential outcomes (Schubik, 1982). It is known as the prisoner's dilemma because it is best explained by reference to two prisoners, interrogated separately, whose jail sentences are dependent on whether they cooperate with the authorities or not, and also on whether the other prisoner does the same. By way of example, the sentences may be as follows:

- If one prisoner cooperates with the authorities and implicates the other prisoner, and the other prisoner says nothing, the cooperating prisoner will go free and the other prisoner will get a ten-year sentence.

- If both prisoners choose not to cooperate with the authorities, both will go to prison for two years each.

- If both prisoners implicate the other, both will go to prison for five years each. 
Table 1 illustrates the potential outcomes from this game based on these example sentences.

Table 1 Potential outcomes in the prisoner's dilemma

\begin{tabular}{|l|l|l|}
\hline & Prisoner B stays silent & $\begin{array}{l}\text { Prisoner B implicates } \\
\text { Prisoner A }\end{array}$ \\
\hline Prisoner A stays silent & $\begin{array}{l}\text { Each prisoner gets a two } \\
\text { year sentence }\end{array}$ & $\begin{array}{l}\text { Prisoner A gets a ten year } \\
\text { sentence; Prisoner B goes } \\
\text { free }\end{array}$ \\
\hline $\begin{array}{l}\text { Prisoner A implicates } \\
\text { prisoner B }\end{array}$ & $\begin{array}{l}\text { Prisoner B gets a ten year } \\
\text { sentence, Prisoner A goes } \\
\text { free }\end{array}$ & $\begin{array}{l}\text { Each prisoner gets a five } \\
\text { year sentence }\end{array}$ \\
\hline
\end{tabular}

The prisoners know the possible outcomes, but do not know what choice the other prisoner will make (i.e. each prisoner's choice is made simultaneously rather than in sequence).

However, whilst the prisoner's dilemma can, in theory, have any one of four different outcomes, both prisoners implicating the other is generally considered the 'solution' in mathematical terms (Colman, 1995), meaning that it is the outcome with the highest probability of occurring, not that it is the best outcome for either player. It is the outcome from which each player could only do worse by unilaterally changing strategy. This outcome is thus known as the 'Nash equilibrium' (based on Nash (1950) cited by Maskin (2011)). Perversely, then, game theory tells us that the 'solution' is the least bad, rather than best, solution for either prisoner. Colman (1995) reports that hundreds of studies have confirmed that players usually choose the Nash equilibrium in the prisoner's dilemma. However, players can act morally and act on the basis of societal, rather than self-interest. So whilst the Nash equilibrium is consistently the most common outcome, it is not the only outcome.

Another classic game is based around the one armed bandit (named after a slot machine with a lever on one side that the game player would pull) whereby the player has a choice of one-armed bandits to play and seeks to maximise returns through trial and error (involving learning). Simon (1959) introduces the binary choice experiment, also called the two-armed bandit. In this game, the player chooses one of two symbols. In Simon's description these are a plus or a minus. If the operator of the game rewards minus two thirds of the time and plus one third of the time, the expectation is, based on self-interest and rational behaviour, that a player would then always select minus and be rewarded two thirds of the time. However, the more common observation is that the player actually chooses minus two thirds of the time - reflecting the frequency of success. So this brings rewards less often than is optimal.

Two other potentially relevant games are dictator and ultimatum games. In the ultimatum game, proposers make an offer and responders can either accept or reject. If the latter, both get nothing. In the dictator game, the proposer has all the power and says what will happen - there is no opportunity for the other player (who has no opportunity to 'play') to choose between outcomes (Kugler et al., 2012). In practice in ultimatum games, the most frequent outcome when the game is played by individuals is that $40 \%$ of whatever 'prize' is considered is offered (with a median of 50\%), and responders reject offers lower than $30 \%$ 
on average (Kugler, 2012), despite game theory suggesting that the proposer should aim to keep nearly all of the 'prize' given that the responder either takes what they are offered or gets nothing. Bornstein and Yaniv (1998) found that where groups played the ultimatum game the proposers offered less and the responders accepted less; i.e. exhibiting more rational behaviour. But in the dictator game, though equity is rare, it still happens (albeit not commonly) - and so some proposers clearly care about equity (Bolton and Ockenfels, 2000).

Colman (1995) distinguishes between different levels of engagement through cooperative and non-cooperative game playing by introducing n-player games, that is, games where there are more than two players. In such cases, three or more players can enter coalitions with each other. In a non-cooperative n-player game each player would decide their strategy independently - that is there would be no coalitions. In cooperative coalitions, there is the possibility for the players to agree their division of payoffs, which places an entirely different dynamic on the situation. Bahn et al. (2009) also distinguish between cooperative and noncooperative types of game theory in their examination of the stability of international environmental agreements. In cooperative theory, all available stakeholders are engaged and stability is defined as when the sharing of benefits is acceptable to all players. This displays deliberative rationality whereby agreement is reached on the acceptability of the outcome. In non-cooperative theory, some are engaged and some are not - and stability is defined as being where engaged players do not choose to leave, and non-engaged players do not choose to join. The assumption is that only a stable international environmental agreement will work and that game theory can help to find how best this might come about. Thus, whilst game theory assumes that the players act rationally on the basis of self-interest only; it can accommodate deliberative rationality through the use of cooperative games. This allows game theory to accommodate societal interests subject to the appropriate diversity of the groups.

Game theory also introduces different behaviour types. Bolton and Ockenfels (2000) refer to standard self-interest game theory reflecting competitive behaviour. As such they argue it is often applied to the behaviour of market organisations. Further they argue that the prisoner's dilemma reflects reciprocity behaviour given that one player is acting reciprocally to the expected plays of another; in this case, both players are acting based on their own self-interest. The importance of equity in some games is also highlighted (Ibid, 2000) and reflects a situation where deliberative rationality is more likely to be applied. The type of behaviour exhibited depends on the game played - which means that the type of behaviour exhibited in environmental assessment-related decisions can be inferred from the game that is most closely matched by the decision context.

Learning from the psychology literature is also relevant to the decisions made by players in game theory. Retief et al. (2015), drawing on Kahneman (2012) to examine the relevance of learning from psychology to EA, identified the importance of 'loss aversion' whereby losses are given more prominence than gains in decision making. The 'solution' in the prisoner's dilemma supports this aversion in that decisions are driven by avoiding greater loss rather than maximising the reward. Retief et al. (2015) also recognised the relevance to EA decision making of the concepts of priming and framing arguing that the way information is presented, or the specific information that is presented prior to a decision being made, is likely to influence the nature of the decision which is made. Framing is especially important because of the way it taps into the underlying value frame of a person or decision maker (Lakoff, 2004). Colman (1995) also discusses framing effects in relation to game theory and cites evidence of significant framing effects amongst game players. 


\section{Methods and analytical framework}

In the following analysis the environmental assessment processes in operation in England at both the project and strategic levels have been used as the case study context for the decision making which will be investigated through application of game theory. England is the chosen case study for three reasons. Firstly, the EIA and SEA legislation has to comply with European Union (EU) Directives, and can therefore be argued to be typical of 28 countries (i.e. the member states of the EU). It should be noted that even within the context of compliance with EU Directives, the specific details of legislation do vary by country even within the EU, and so the analysis could be different in other jurisdictions. Secondly, the environmental assessment systems are mature, well-researched and well understood. This makes it easier for other researchers to understand the analysis presented and helps to make it more transparent. Thirdly, the authors are familiar with the procedures and from a pragmatic perspective are better placed to conduct the analysis. To simplify the analysis, the paper focuses on EIA within the land use planning sector only as governed by Government regulations (United Kingdom Parliament, 2011) as these regulations account for between 60 and $70 \%$ of all EIAs conducted in the UK across all sectors (Glasson et al., 2012).

In order to meet the aims set out in section 1, there is a need to conceptualise the role of environmental assessment in decision-making - given that EA is a decision-support tool rather than a decision-making tool. It is then possible to develop an analytical framework after Yin $(2003 ; 2012)$ given that a case study context provides the basis for the analysis.

In conceptualising the role of environmental assessment in decision-making, Dalkmann et al. (2004) recognised the importance of decision theory to the practice of strategic environmental assessment (SEA), given that SEA is also designed to influence decisions. They proposed a new form of SEA encompassing decision theory which they called Analytical Strategic Environmental Assessment (ANSEA). A key part of their ANSEA process was a specific stage that involved the identification of decision windows (DW) - the points at which the ANSEA process would interface with the decision-making process. These windows are the opportunities for EA to have any influence on the outcomes.

Project-level EIA in England is well detailed in Glasson et al. (2012) and it is beyond our scope to explain the full process here. Salient characteristics pertain to a set of DWs for English EIA, which in our opinion, looks as follows:

DW1 - screening - does the proposal require environmental assessment?

DW2 - scoping - what should the environmental assessment focus on?

DW3 - project approval decision - are the impacts acceptable (based on the ElA carried out and its report)?

Screening and scoping are decisions made about the EIA process itself, with local authorities being the decision makers - where the tasks are usually delegated by planning committees to individual planning officers. Planning committees comprising elected representatives of local authorities typically make the project decision. Depending on the specific legal requirements and/or practice, there may be more (or fewer) decision windows. However, 
these three are likely to characterise the majority of environmental assessment systems globally and provide a suitable basis for exploration using game theory.

The decision windows at strategic level may be different. This paper focuses again on England where a process called Sustainability Appraisal operates at the strategic level (for land use, or spatial, plans). Sustainability Appraisal is described in more detail in Therivel and Fischer (2012); Therivel (2013); Hayes et al. (2014); Hayes and Fischer (2015). A set of decision windows for English Sustainability Appraisal looks as follows:

DW1 - scoping - what should the environmental assessment focus on?

DW2 - plan proposal - what should the plan look like (based on the environmental assessment carried out and its report)?

To investigate the research aim, each decision window in the case study context is evaluated based on an analytical framework based on game theory. Where the case study context fits the theory, our understanding of the principles and assumption underpinning game theory will allow us to better understand the nature of the decision making taking place and allow us to comment on the extent to which instrumental rationality or deliberative rationality is applied. That is, the analysis allows us to estimate the likely legitimacy of the decision in contexts where values are contested. Thus the following games will be considered for their 'fit' with decision making, from which we can draw learning about the legitimacy of decisiontaking in the decision windows:

- Cake slicing;

- Prisoner's dilemma;

- Zero-sum game;

- One-armed bandit;

- Ultimatum; and

- Dictator.

To characterise each game, alternative behaviour types exhibited within the game can be distinguished. The behaviour type tells us the extent to which the values considered are those of an individual or a group of decision-makers acting in unison (reflecting instrumental rationality), those of two players actively reflecting on the values of the other (also reflecting instrumental rationality), or those of a wider set of values that might be expected from the full range of stakeholders, including the public, that could be involved in a decision window (reflecting deliberative rationality) and might be more likely to legitimise any decision made. There are three behaviour types:

- competitiveness;

- reciprocity; or

- equity.

The decision timing is critical as games can be played simultaneously, or in sequence. In the former, the players will anticipate what the others will do, and make their own decisions at the same time. In the latter, one player will make their move, and the next will then decide 
their move based on the new situation. The differences are stark - one timing is based purely on anticipation and prediction and therefore not transparent, the other on some knowledge (albeit still with some anticipation), reflecting transparency (which is a necessary ingredient of legitimacy (Jasanoff, 1997)). Sequential decision-making better reflects principles of good public participation as embodied in legal instruments like the Århus Convention (United Nations Economic Commission for Europe, 1998) and, based on arguments made in the introduction, are more likely to encourage deliberation and lead to legitimacy. The two decision timing characteristics are thus:

- simultaneous; or

- sequential.

Each game introduced in the previous section exhibits particular decision timing and behaviour type characteristics as set out in Table 2 . Hence an understanding of which game best fits each decision window allows us to draw conclusions about the decision timing and behaviour type which are characterising the decision made.

Table 2 Typical decision timing and behaviour types of different games

\begin{tabular}{|ll|ll|ll|}
\hline Relevant game* & \multicolumn{2}{l|}{ Decision timing } & \multicolumn{2}{l|}{ Behaviour type } \\
\hline$\bullet$ & Cake slicing & $\bullet$ & sequential & $\bullet$ & reciprocity \\
\hline$\bullet$ & $\begin{array}{l}\text { Prisoner's } \\
\text { dilemma }\end{array}$ & $\bullet$ & simultaneous & $\bullet$ & reciprocity \\
\hline$\bullet$ & Zero-sum game & $\bullet$ & simultaneous & $\bullet$ & competitiveness \\
\hline$\bullet$ & $\begin{array}{l}\text { One-armed } \\
\text { bandit }\end{array}$ & $\bullet$ & sequential & $\bullet$ & competitiveness \\
\hline$\bullet$ & Ultimatum & $\bullet$ & sequential & $\bullet$ & reciprocity \\
& & & & & \\
\hline$\bullet$ & Dictator & $\bullet$ & sequential & $\bullet$ & reciprocity \\
& & & & & \\
\hline
\end{tabular}

* NB the game can be subject to loss aversion or framing effects, which could affect the behaviour type

We have previously explained that there are different levels of engagement in game theory (Colman, 1995):

- cooperative; and

- non-cooperative.

These are important because they reflect the extent to which instrumental rationality applies (and to which Nash's equilibrium applies as this is generally applied to noncooperative games), and the extent to which wider stakeholder values can be embedded which will likely involve the use of deliberative rationality. So for the games considered, 
whilst they may typically be played in non-cooperative ways, it is possible for them to be played cooperatively. A judgement on the level of engagement therefore has to be made independently for each decision window based on the characteristics of that decision. Note that Table 2 assumes instrumental rationality is applied in line with game theory and so no game is defined as exhibiting equity as a behaviour type. Subject to sufficient levels of engagement (see below) it may be possible for deliberative rationality to be exhibited in a game which could change the behaviour type listed.

Taken overall then, the analytical framework assumes that a particular combination of level of engagement, behaviour type and decision timing is more likely to lead to legitimacy: i.e. those which deliver equity, are cooperative, and sequential. Table 3 sets out the analytical framework for the analysis. For each decision window, the relevant game will predetermine the decision timing and behaviour type; the relevant level of engagement also needs to be identified and the extent to which this has affected the behaviour type considered. This then facilitates an analysis of the extent to which the decision in any decision window is legitimate.

Table 3 Analytical framework

\begin{tabular}{|l|l|l|l|l|}
\hline & Relevant game & Decision timing & Behaviour type & $\begin{array}{l}\text { Levels of } \\
\text { engagement }\end{array}$ \\
\hline DW1 & & & & \\
\hline DW2 & & & & \\
\hline DW3 & & & & \\
\hline DW... & & & & \\
\hline
\end{tabular}

The evaluations made in the next section are clearly heavily contingent both on the decision windows identified for the two types of environmental assessment and also on the analytical framework developed above. Changes to either of these will change the analysis. However, efforts have been made to stick to general principles and assumptions which are widely reported. The most critical assumptions that observers could question are:

1) An inherent assumption in game theory is that players often act in self-interest and do so rationally (although section 2 indicated that this is not always the case). This is a key assumption given that not all authors feel that game theory applies to environmental assessment because of it; for example, Kørnøv and Thissen (2000) refer to empirical evidence demonstrating the invalidity of game theory given its assumption of instrumentally rational behaviour. One could argue that the key decision-makers in this analysis, the local authorities, are public servants. As such it can be argued that self-interest and societal interest are the same thing in terms of their job description. Nevertheless, research by Cheng et al. (2007), albeit in a very different legislative context, identified that authorities (in China) were prioritising short-term economic gain over long-term societal benefits. It is the case that authorities will benefit from rates paid by businesses operating in their geographical 
area - which could be argued to incentivise development, albeit the rate income will be spent on projects benefitting the population living within the authority's boundaries. Our analysis will assume decision-makers act rationally on the basis of self-interest, unless the opportunities arise to ensure deliberative rationality applies instead. We assume that the extent to which this might happen is controlled by the decision timing, the behaviour type and the level of engagement.

2) The assumption that complex, real-life decision-making can be modelled accurately by a game is open to debate. Predicting human motivations and preferences in the light of different value systems, in an additional context of poorly understood natural systems with large uncertainty inherent in any information fed to decision makers, is fraught with difficulty. Nevertheless, game theorists continue to strive to explain decision making using assumptions that can be mathematically modelled. Our research does not aim to make accurate predictions. Rather we seek to examine the applicability of the basic assumptions in order to learn about the legitimacy of existing decisions and to be able to comment on the extent to which it may be jeopardised where powerful interests apply their own instrumental rationality to the process.

3) The evaluation made on the basis of the game theory analytical framework and the environmental assessment decision windows is inherently subjective. Other observers are at liberty to make different arguments and reach different conclusions.

\section{Game theory and environmental assessment decision windows - what does it tell us?}

Table 4 evaluates the decision windows for project level EIA conducted within the land use planning sector in England against the analytical framework developed in the previous section.

Table 4 Games that best match project EIA

\begin{tabular}{|l|l|l|l|l|}
\hline & Relevant game & Decision timing & $\begin{array}{c}\text { Behaviour } \\
\text { type }\end{array}$ & $\begin{array}{c}\text { Level of } \\
\text { engagement }\end{array}$ \\
\hline $\begin{array}{l}\text { DW1 - } \\
\text { Screening }\end{array}$ & $\begin{array}{l}\text { Dictator (with } \\
\text { framing } \\
\text { effects?) }\end{array}$ & Sequential & Reciprocity & Non-cooperative \\
\hline DW2 - Scoping & $\begin{array}{l}\text { Ultimatum (with } \\
\text { framing } \\
\text { effects?) }\end{array}$ & Sequential & Reciprocity & Non-cooperative \\
\hline $\begin{array}{l}\text { DW3 - Project } \\
\text { approval } \\
\text { decision }\end{array}$ & $\begin{array}{l}\text { Ultimatum / } \\
\text { dictator }\end{array}$ & Sequential & Reciprocity & Non-cooperative \\
\hline
\end{tabular}


For project EIA, then, we see a very limited set of relevant games. For screening, the typical practice might be for the developer (perhaps through their consultants) to provide information to the local authority, who will make a screening determination (where discretion is allowed by the legislation - which it is in the majority of cases). Ultimately, the decision is down to the local authority, typically a planning officer operating under powers delegated by the elected planning committee. So an individual provides a definitive yes or no answer. The developer can appeal the decision, but it is basically an example of the dictator game where the decision is sequential to receiving information and in this sense is non-cooperative. One concern is that the developer will likely frame their dialogue with the decision maker according to the outcome they wish to see, for example to influence the decision maker's exercise of discretion in relation to screening. Broader engagement could act as a counterweight to such framing.

For scoping, again the developer will likely produce a scoping report to frame the decision made by the local authority. The local authority will seek additional views before deciding the scope - and so they make a sequential decision. The scoping opinion will ultimately be that provided by a planning officer and provides a template to the developer. In this way it provides them with an ultimatum - deliver this information or a determination of the planning application will not be made (until the information is provided). The scoping opinion depends on the cooperation of potentially diverse stakeholders, including the public, but is ultimately made by the local authority alone, providing it can be justified. As such it is a non-cooperative decision. Herein lies the paradox of public participation in the EIA process. The developer will often have sought views of the public in setting out their proposed scope and so within the EIA process there may be significant cooperation and transparency. This may or may not inform the decision in the decision window.

After the EIA has been completed and the local authority receives the environmental report, the project approval decision is made by a planning committee. At that stage it becomes a group decision which we have seen can reinforce the application of instrumental rationality. It is not cooperative in involving coalitions of wider stakeholders. A refusal of permission reflects the dictator game - there is no discussion or compromise possible (beyond legal appeal). However, granting permission is usually subject to planning conditions, so contingent on certain things being done which have to be acceptable to the developerotherwise nothing will get built; this makes it equivalent to the ultimatum game.

So in terms of game theory, project EIA is typically non-cooperative, and characterised by a lack of opportunity to deliberate and achieve equity. And in referring to equity, there are two key players involved - the local authority and the developer - so equity has a limited interpretation which relies on the local authority acting on behalf of society in order to be fully equitable. So game theory suggests EIA is unlikely to deliver legitimacy in its current format in the UK; it can deliver it where the decision maker(s) act on the basis of societal interests - but there are no actual mechanisms facilitating the application of deliberative rationality. The sequential nature of the game - whereby decisions are made after information exchanges hands, is in line with the information processing model of Environmental Impact Assessment (Bartlett and Kurian, 1999), which is specifically based on the assumption of rational decision-making based on the evidence of the implications. However, when viewed through the lens of game theory, the opportunity for the information to be framed in favour of one outcome in the decision windows, calls into question the extent to which wider societal values are considered. 
We might postulate that the processes could be better designed if reliance on the decision maker acting in societal interest were not required. That is, an environmental assessment process which is better integrated into the decision system is needed. This is not a new finding (see, for example, Warner, 1996; van Stigt et al., 2013; Sánchez, 2014) but this analysis does help to clarify the specific problems that might arise through the use of a rational-technical model which assumes decision making delivers legitimacy, but cannot guarantee it.

Sustainability Appraisal in England is different from project EIA. It is a process conducted to try and address the three pillars of sustainability, whilst being compliant with the Strategic Environmental Assessment (SEA) Directive (European Parliament and the Council of the European Union, 2001). Fundingsland Tetlow and Hanusch (2012) make the point that SEA is generally regarded as having more potential to be proactive in ensuring sustainability outcomes than project-level EIA given the nature of the plans and programmes which are assessed, that control and facilitate future projects that will be subject to EIA. Given the analysis using game theory (See Table 5), this does seem to hold true.

Table 5 Games that best match Sustainability Appraisal

\begin{tabular}{|l|l|l|l|l|}
\hline & Relevant game & Decision timing & Behaviour type & $\begin{array}{c}\text { level of } \\
\text { engagement }\end{array}$ \\
\hline DW1 - Scoping & $\begin{array}{l}\text { Dictator (with } \\
\text { framing } \\
\text { effects?) }\end{array}$ & Sequential & Reciprocity & $\begin{array}{l}\text { Cooperative } \\
\text { (potentially) }\end{array}$ \\
\hline $\begin{array}{l}\text { DW2 - Plan } \\
\text { proposal }\end{array}$ & $\begin{array}{l}\text { Prisoner's } \\
\text { dilemma } \\
\text { One-armed } \\
\text { bandit }\end{array}$ & Sequential & $\begin{array}{l}\text { Reciprocity / } \\
\text { competitiveness }\end{array}$ & $\begin{array}{l}\text { Cooperative } \\
\text { (potentially) }\end{array}$ \\
\hline
\end{tabular}

At the scoping stage, practice varies as to the extent to which a diverse stakeholder set would be involved in establishing the sustainability objectives against which to appraise the emerging land use plan (Giddings et al., 2010; Therivel and Fischer, 2012; Thérivel, 2013). There is the potential for this to be a cooperative process, but it can also be much more restricted and constrained to the local authority developing the plan and/or their consultants. There is a final decision on the scope which would reside with those conducting the appraisal - so the most likely situation is for the scope to be framed by other stakeholders but then approved by the decision maker.

For the plan proposal, i.e. the plan which has been prepared based on the findings of the appraisal, there is more than one game at play. The core strategy element of the plan comprises a number of policies which constrain the consideration of development control applications (once the plan is adopted). To get to the preferred policy, draft policies are appraised against the sustainability appraisal objectives. So for each policy area, there is an element of prisoner's dilemma because only one preferred policy can be chosen, and decisions will need to be taken based on the evidence provided by the appraisal. This is a situation where the most beneficial policy might not win if there are different values at play - it is possible for the least unacceptable policy to those involved being the one selected 
(Nash's equilibrium). This suggests elements of reciprocity are potentially at play, based on sequential consideration of evidence, likely in a cooperative environment (to an extent). An alternative game that might apply is the one-armed bandit in that the choices of plan policy options tend to follow particular approaches. An example is given in Table 6 from advice written for transport planners (Simmons, 2004). It is possible, where such approaches are used, for the decision makers to favour particular approaches irrespective of the evidence underpinning them - which is similar to one-armed bandit games.

Table 6 Possible approaches for developing plan policy options. Adapted from: Simmons (2004)

\begin{tabular}{|c|c|}
\hline Approach & Alternative options \\
\hline Timing of funding & $\begin{array}{l}\text { 1. Low cost measures first } \\
\text { 2. High cost measures first } \\
\text { 3. Even split of funding }\end{array}$ \\
\hline Cost of measure & $\begin{array}{l}\text { 1. Soft measures (information and advice) } \\
\text { 2. Demand management (physical and fiscal) } \\
\text { 3. Physical improvements to existing network } \\
\text { 4. Expand network }\end{array}$ \\
\hline Geographic split & $\begin{array}{l}\text { 1. Apportionment of funding based on planned population } \\
\text { growth } \\
\text { 2. Apportionment of funding based on most deprived wards } \\
\text { 3. Apportionment of funding based on accessibility to } \\
\text { transport network }\end{array}$ \\
\hline $\begin{array}{l}\text { Relationship with } \\
\text { strategic network }\end{array}$ & $\begin{array}{l}\text { 1. Prioritise measures to complement other authorities' } \\
\text { investments in strategic transport network } \\
\text { 2. Prioritise measures based on local needs }\end{array}$ \\
\hline Population growth & $\begin{array}{l}\text { 1. Delivery of measures based on a static population } \\
\text { 2. Delivery of measures based on a "low range" population } \\
\text { forecast } \\
\text { 3. Delivery of measures based on a "high range" population } \\
\text { forecast }\end{array}$ \\
\hline
\end{tabular}

Thus for Sustainability Appraisal there is more opportunity for cooperative approaches in decision making than in EIA. Given Cashmore's (2004) arguments that philosophical beliefs and values related to the role of science in EIA occurs on a spectrum, this suggests that Sustainability Appraisal is closer to the conditions for legitimacy than is EIA. However, like for EIA, delivering legitimacy really depends on the decision makers acting on behalf of society, which is not guaranteed. We have suggested that legitimacy requires a process which is sequential, cooperative and exhibits equity. The design of Sustainability Appraisal means this is more likely than for EIA, but that it is still not built into the design process - it relies on game players acting in particular ways.

The application of prisoner's dilemma and one-armed bandit games (again assuming instrumental rationality) at the strategic decision-making level suggests that there exists the propensity to achieve Nash's equilibrium and select solutions which are least bad, rather those which are most sustainable. This finding is counter to that of Prenzel and Vanclay (2014) who drew on the prisoner's dilemma in arguing that the outcome of a potential 
conflict between two parties depends on their approach to the potential conflict; they can either choose concession or escalation. Any individual party can choose escalation and, if the other party seeks concession, they are likely to gain as a result of this strategy (this would be a win-lose situation). However, if one party seeks escalation, then the other may also seek escalation in order to not be relatively disadvantaged - the outcome of escalated conflict for both parties is likely to be poor - so this is a lose-lose situation. They define concession by both parties as win-win which they argue can be facilitated by social impact assessment. Interestingly, this definition is at odds with what is considered the "solution" in the prisoner's dilemma (which is for both parties to escalate). So win-win from a societal point of view may be unlikely according to game theory under conditions where the prisoner's dilemma is valid (which is simultaneous and secret decision-making exhibiting instrumental rationality). The push for dialogue that should accompany any form of environmental assessment could ensure these conditions are not met; that is, a move towards greater transparency and deliberation would be needed to prevent the Nash equilibrium prevailing. Again this is not currently guaranteed by the legislation.

\section{Conclusions}

In this paper we drew on game theory to understand where instrumental rationality is applied in the environmental assessment process, and where deliberative rationality can be applied through participation in decision-making, thereby increasing the legitimacy of environmental assessment. We argue that legitimacy is dependent on the timing of decision information, the behaviour type exhibited by the decision maker and the level of public engagement. We recognise that providing the opportunity for legitimacy is not the same as ensuring legitimacy. Thus, whilst we might expect the conditions for legitimacy would be met if the decision timing was sequential, the behaviour type emphasised equity and the engagement was cooperative, the socially constructed nature of legitimacy means that this is not guaranteed; our conceptualisation may be incomplete and could miss some essential context-specific variables that also influence legitimacy, and could also miss some games which better describe the decision windows. Conversely, we would regard it as possible for simultaneous decision-making based on competitive behaviour conducted in a noncooperative way raise no legitimacy issues, but only in case which are not contentious.

Our analysis has remained largely theoretical and so we have not investigated the actual decisions made in specific cases. Instead we have analysed what is likely to happen and what can happen within the legal framework for environmental assessment in the case study context. It is thus unclear whether decision makers actually apply instrumental rationality or deliberative rationality.

The discipline of considering game theory has led to a focus on the actual decision made on the intervention which is the subject of the environmental assessment, rather than the decisions made within the environmental assessment. Much is written about the extent to which environmental assessment engages diverse stakeholders (e.g., Petts, 1999; Palerm, 2000; Doelle and Sinclair, 2006; O'Faircheallaigh, 2010), but this analysis suggests this misses the point - environmental assessment does not make decisions - it informs decision makers. Analysis in relation to game theory reveals some stark omissions in terms of the ability of environmental assessment to guarantee the legitimacy of decisions. The results also 
substantiate the arguments of researchers who consider SEA to be much more likely to achieve better outcomes than EIA.

According to Maskin (2011, p.9) Nash's equilibrium is based very much in the noncooperative line of theory as it pertains to the choice of an individual. Maskin considers flaws in Nash's equilibrium and introduces the concept of 'mechanism design', whereby the desired goals are known, but the game that has the equilibrium point as that goal (as opposed to others) is not known. Mechanism design is potentially a useful approach for moving from the reality of playing out a game to an understanding of what game should be played (i.e. how decisions should be made in order to achieve the desired outcome). Thus, assuming a goal of legitimate decision-making is appropriate, the question we should be asking is "what game can deliver legitimate decision-making as the Nash's equilibrium?" This potentially provides a means of critically analysing existing decision window processes in environmental assessment with a view to changing them to reflect the 'right' game characteristics. Thus we suggest that mechanism design could provide a useful approach for designing the operation of decision windows to achieve legitimacy in environmental assessment within the context of the stated goals of the process.

Our analysis suggests that EA does function as originally intended - to apply instrumental rationality to decision making. However, the inability of the technical-rational model to deal with the more contested goals of sustainable development has led to calls for deliberative rationality to be applied. The application of game theory has suggested that EA in its current form is not designed for deliberation and will continue to suffer from legitimacy problems.

\section{References}

Adger, W N, N W Arnell and E L Tompkins (2005), "Successful adaptation to climate change across scales", Global Environmental Change, 15(2), pages 77-86.

Agterbosch, S and S Breukers (2008), "Socio-political embedding of onshore wind power in the Netherlands and North Rhine-Westphalia", Technology Analysis and Strategic Management, 20(5), pages 633-648.

Appelstrand, M (2002), "Participation and societal values: The challenge for lawmakers and policy practitioners", Forest Policy and Economics, 4(4), pages 281-290.

Bahn, O, M Breton, L Sbragia and G Zaccour (2009), "Stability of international environmental agreements: an illustration with asymmetrical countries", International Transactions in Operational Research, 16(3), pages 307-324.

Bartlett, R V and P A Kurian (1999), "The Theory of Environmental Impact Assessment: Implicit models of policy making", Policy \& Politics, 27(4), pages 415-433.

Bolton, G E and A Ockenfels (2000), "ERC: A theory of equity, reciprocity, and competition", American Economic Review, 90(1), pages 166-193.

Bornstein, G and I Yaniv (1998), "Individual and group behavior in the ultimatum game: Are groups more "rational" players?", Experimental Economics, 1(1), pages 101-108.

Cashmore, M (2004), "The Role of Science in Environmental Impact Assessment: Process and Procedure versus Purpose in the Development of Theory", Environmental Impact Assessment Review, 24(4), pages 403-426.

Cashmore, $M$ and A Axelsson (2013), "The mediation of environmental assessment's influence: What role for power?", Environmental Impact Assessment Review, 39, pages 5-12. 
Cashmore, M, A Bond and D Cobb (2008), "The role and functioning of environmental assessment: Theoretical reflections upon an empirical investigation of causation", Journal of Environmental Management, 88(4), pages 1233-1248.

Cheng, H, Y Qi, X Pu and L Gong (2007), "Game theoretic analysis of environmental impact assessment system in China", Frontiers of Environmental Science and Engineering in China, 1(4), pages 448-453.

Colman, A M (1995), Game Theory and Its Applications in the Social and Biological Sciences (Butterworth Heinemann, Oxford).

Dalkmann, H, R J Herrera and D Bongardt (2004), "Analytical strategic environment assessment (ANSEA) developing a new approach to SEA", Environmental Impact Assessment Review, 24(4), pages 385-402.

Doelle, M and A J Sinclair (2006), "Time for a new approach to public participation in EA: promoting cooperation and consensus for sustainability", Environmental Impact Assessment Review, 26(2), pages 185-205.

European Parliament and the Council of the European Union (2001), "Directive 2001/42/EC of the European Parliament and of the Council of 27 June 2001 on the assessment of the effects of certain plans and programmes on the environment", Official Journal of the European Communities, L197, pages 30-37.

Fundingsland Tetlow, M and M Hanusch (2012), "Strategic environmental assessment: the state of the art", Impact Assessment and Project Appraisal, 30(1), pages 15-24.

Giddings, B, G Porter, E Paterson and K Theobald (2010), "Participation in sustainability appraisal planning policy", Proceedings of the Institution of Civil Engineers: Municipal Engineer, 163(2), pages 115-123.

Glasson, J, R Therivel and A Chadwick (2012), Introduction to Environmental Impact Assessment (Routledge, London).

Hayes, S, A Barker and C Jones (2014), "Flood management consideration in sustainability appraisal and strategic environmental assessment in England and Scotland", Journal of Environmental Assessment Policy and Management, 16(3).

Hayes, $\mathrm{S}$ and T Fischer (2015), "Setting and measuring objectives in sustainability assessment", in A Morrison-Saunders, J Pope and A Bond (editors), Handbook of Sustainability Assessment (Edward Elgar, Cheltenham).

International Association for Impact Assessment and Institute of Environmental Assessment (1999), "Principles of Environmental Impact Assessment Best Practice", available at <http://iaia.org/publicdocuments/special-publications/Principles of IA_web.pdf\%3E, last accessed 27 November 2013.

Jasanoff, S (1997), "Civilization and madness: the great BSE scare of 1996", Public understanding of science, 6(3), pages 221-232.

Jensen, $T$ (2007), "Moral responsibility and the business and sustainable development assemblage: A Jonasian ethics for the technological age", International Journal of Innovation and Sustainable Development, 2(1), pages 116-129.

Kahneman, D. (2012), Thinking, Fast and Slow, London: Penguin.

Kørnøv, L (2015), "Faces and functions of theory in impact assessment research", Journal of Environmental Assessment Policy and Management, 17(1).

Kørnøv, L and W A H Thissen (2000), "Rationality in Decision- and Policy-Making: Implications for Strategic Environmental Assessment", Impact Assessment and Project Appraisal, 18(3), pages 191-200.

Kugler, T, E E Kausel and M G Kocher (2012), "Are groups more rational than individuals? A review of interactive decision making in groups", Wiley Interdisciplinary Reviews: Cognitive Science, 3(4), pages 471-482. 
Lakoff, G (2004). "Don't Think of an Elephant! Know Your Values and Frame the Debate. the Essential Guide for Progressives, Including Post-Election Updates". (White River Junction, Vermont: Chelsea Green).

Maskin, E (2011), "Commentary: Nash equilibrium and mechanism design", Games and Economic Behavior, 71(1), pages 9-11.

Morgan, R K (2012), "Environmental impact assessment: the state of the art", Impact Assessment and Project Appraisal, 30(1), pages 5-14.

Myerson, R B (1991), "Game theory: analysis of conflict", Cambridge: Mass, Harvard University.

Nash, J F (1950), "Equilibrium points in n-person games", Proc. Nat. Acad. Sci. USA, 36(1), pages $48-49$.

O'Faircheallaigh, C (2010), "Public participation and environmental impact assessment: purposes, implications, and lessons for public policy making", Environmental Impact Assessment Review, 30(1), pages 19-27.

Owens, S, T Rayner and O Bina (2004), "New agendas for appraisal: reflections on theory, practice, and research", Environment and Planning A, 36(11), pages 1943-1959.

Palerm, J R (2000), "An Empirical-Theoretical Analysis Framework for Public Participation in Environmental Impact Assessment", Journal of Environmental Planning and Management, 43(5), pages 581-600.

Petts, J (1999), "Public participation and environmental impact assessment", in J Petts (editor) Handbook of Environmental Impact Assessment - Vol.1 Environmental Impact Assessment: Process, Methods and Potential (Blackwell Science, Oxford) pages 145-177.

Pope, J, A Bond, A Morrison-Saunders and F Retief (2013), "Advancing the theory and practice of impact assessment: Setting the research agenda", Environmental Impact Assessment Review, 41, pages 1-9.

Poundstone, W (1992). "Prisoner's Dilemma: John von Neuman, Game Theory, and the Puzzle of the Bomb". (Doubleday, New York).

Prenzel, P V and F Vanclay (2014), "How social impact assessment can contribute to conflict management", Environmental Impact Assessment Review, 45, pages 30-37.

Retief, F, A Morrison-Saunders, J Pope and A Bond (2015), "Key learnings from psychology for sustainability assessment", in A Morrison-Saunders, J Pope and A Bond (editors), Handbook of Sustainability Assessment (Edward Elgar, Cheltenham).

Sánchez, LE (2014), "From neighbors to future generations: we are all together! On integration in impact assessment practice", Impact Assessment and Project Appraisal, 32(1), pages 14-16.

Schubik, M (1982), Game-theory in the social sciences: concepts and solutions (MIT Press, Massachusetts).

Sheate, W R (2012), "Purposes, paradigms and pressure groups: Accountability and sustainability in EU environmental assessment, 1985-2010", Environmental Impact Assessment Review, 33(1), pages 91-102.

Simmons, S (2004), "Setting and measuring objectives in sustainability assessment", available at <http://www.seainfo.net/files/general/sup_advice_on_selecting_and_doc_alternatives.PDF\%3E, last accessed July 15th 2015.

Simon, H A (1959), "Theories of decision-making in economics and behavioral science", The American economic review, pages 253-283.

Stolp, A, W Groen, J van Vliet and F Vanclay (2002), "Citizen values assessment: incorporating citizens' value judgements into environmental impact assessment", Impact Assessment and Project Appraisal, 20(1), pages 11-23. 
Suchman, M C (1995), "Managing legitimacy: Strategic and institutional approaches", Academy of management review, 20(3), pages 571-610.

Therivel, R (2013), "Use of sustainability appraisal by English planning inspectors and judges", Environmental Impact Assessment Review, 38, pages 26-34.

Thérivel, R (2013), "Chapter 9: Sustainability assessment in England", in A Bond, A MorrisonSaunders and R Howitt (editors), Sustainability Assessment: Pluralism, Practice and Progress (Taylor and Francis, London) pages 132-148.

Therivel, R and T Fischer (2012), "Sustainability Appraisal in England", UVP-Report, 26(1), pages 16-21.

United Nations Economic Commission for Europe (1998), Convention on access to information, public participation in decision-making and access to justice in environmental matters (United Nations Economic Commission for Europe, Committee on Environmental Policy, Geneva) 28.

United Kingdom Parliament (2011), The Town \& Country Planning (Environmental Impact Assessment) Regulations 2011, SI No. 1824 (HMSO, London).

van Stigt, R, P P J Driessen and T J M Spit (2013), "A window on urban sustainability. Integration of environmental interests in urban planning through 'decision windows'", Environmental Impact Assessment Review, 42, pages 18-24.

Warner, M (1996), "Integration of regional land use planning with environmental impact assessment: practical land suitability assessment approach", Impact Assessment, 14(2), pages 155-190.

Yin, R K (2003), Case Study Research: Design and Methods (Sage, London).

Yin, R K (2012), Applications of Case Study Research (Sage Publications Ltd., Thousand Oaks, California). 